\title{
Cell Type-Specific Activation of Neuronal Nicotinic Acetylcholine Receptor Subunit Genes by Sox10
}

\author{
Qun Liu, Irena N. Melnikova, Minjie Hu, and Paul D. Gardner \\ Department of Molecular Medicine, University of Texas Health Science Center, San Antonio, Texas 78245-3207
}

The regulatory factor Sox10 is expressed in neural crest derivatives during development as well as in the adult CNS and peripheral nervous system. Mutations of the human Sox10 gene have been identified in patients with WaardenburgHirschsprung syndrome that is characterized by defects in neural crest development. Previous studies suggested that Sox10 might function as an important transcriptional regulator of neural crest development. No natural target genes of Sox10 have yet been identified. Although human Sox10 activates a synthetic promoter consisting of a TATA box and multiple Sox consensus sequences, no transcriptional activity of the rat Sox10 homolog has been detected. Here we report that the neuronal nicotinic acetylcholine receptor $\beta 4$ and $\alpha 3$ subunit gene promoters are transactivated by rat Sox10 in a cell typespecific manner. The $\alpha 3$ and $\beta 4$ subunits, in combination with the $\alpha 5$ subunit, make up the predominant nicotinic receptor subtype expressed in the peripheral nervous system. Transfections using Sox10 mutants indicate that the $\mathrm{C}$-terminal region is dispensable for its ability to activate the $\beta 4$ and $\alpha 3$ promoters. Rat Sox10 was originally identified as an accessory protein of the POU domain protein Tst-1/Oct6/SCIP in glial cells. Tst-1/ Oct6/SCIP was shown previously to activate the $\alpha 3$ promoter. We now demonstrate that it can transactivate the $\beta 4$ promoter as well. However, we were unable to detect any synergistic effects of Sox10 and Tst-1/Oct6/SCIP on $\beta 4$ or $\alpha 3$ promoter activity. Finally, we present data suggesting that recombinant Sox10 protein can directly interact with a previously characterized regulatory region of the $\beta 4$ gene.

Key words: Sox10; gene expression; nACh receptor; ligandgated ion channel; transcriptional regulation; $P O U$
Eleven members of the gene family encoding neuronal nicotinic acetylcholine (nACh) receptor subunits have been identified and include $\alpha 2-\alpha 9$ and $\beta 2-\beta 4$ (Boyd, 1997). These subunits form heteromeric and homomeric receptors with distinct pharmacological and physiological profiles (Schoepfer et al., 1990; Elgoyhen et al., 1994; McGehee and Role, 1995; Role and Berg 1996; Gerzanich et al., 1997). The functional diversity exhibited by the neuronal $\mathrm{nACh}$ receptor family results in large part from the differential expression of the subunit genes and the subsequent incorporation of the subunits into mature receptors. The molecular mechanisms leading to formation of the various nACh receptor subtypes remain to be completely elucidated. However, it is clear that regulation at the level of transcription plays an important role (Boyd, 1997).

Our previous work focused on transcriptional regulation of three genomically clustered receptor genes, those encoding the $\beta 4, \alpha 3$, and $\alpha 5$ subunits. These three subunits make up the predominant receptor subtype expressed in the peripheral nervous system (PNS) (Conroy et al., 1993; Conroy and Berg, 1995). We and others have identified several cis-acting elements (Boyd,

Received April 22, 1999; revised Aug. 30, 1999; accepted Sept. 1, 1999.

This work was supported by grants to P.D.G. from The National Institutes of Health, The Council for Tobacco Research USA, and The Smokeless Tobacco Research Council, Inc. I.N.M. was supported by a POW RE grant from The National Science Foundation. We thank Jim Boulter, Patrick Burrola, Kirsten Kuhlbrodt, Greg Lemke, and Michael Wegner for generously providing reagents and Katie Reidel and Shyun Li for help during the early phases of this work. P.D.G. thanks B. P. and D. R. for inspiration.

Q.L. and I.N.M. contributed equally to this work.

Correspondence should be addressed to Dr. Paul D. Gardner, Department of Molecular Medicine, University of Texas Health Science Center, 15355 Lambda Drive, San Antonio, TX 78245-3207. E-mail: gardner@uthscsa.edu.

Dr. Hu's present address: Department of Neurobiology, Stanford University School of Medicine, Stanford, CA 94305-5125.

Copyright (C) 1999 Society for Neuroscience 0270-6474/99/199747-09\$05.00/0
1994; Yang et al., 1994, 1997; Hu et al., 1995; Bigger et al., 1996; Fornasari et al., 1997; McDonough and Deneris, 1997) and transacting proteins (Yang et al., 1995; Fyodorov and Deneris, 1996; Milton et al., 1996; Bigger et al., 1997; Du et al., 1997, 1998; Fyodorov et al., 1998; Campos-Caro et al., 1999) that are important for the transcriptional regulation of the clustered genes. However, the mechanisms underlying the neuron-specific expression of the receptor genes remain elusive.

Recently, a novel member of the Sox protein family, Sox10, was identified (Kuhlbrodt et al., 1998a). Sox proteins have been implicated as important transcriptional regulators in a variety of developmental processes (Gubbay et al., 1990; Denny et al., 1992; Wright et al., 1993; Kamachi et al., 1995). Sox10 has been proposed to function as an important regulator during neural crest development (Bondurand et al., 1998). Consistent with this hypothesis is the demonstration that a Sox10 gene mutation in the Dominant megacolon (Dom) mouse gives rise to aganglionosis of the colon and pigmentation defects as well as to substantial losses of neurons and glia in the PNS and a complete loss of the enteric nervous system (Herbarth et al., 1998; Southard-Smith et al., 1998). Additionally, SOX10 mutations have been detected in patients with Waardenburg-Hirschsprung syndrome, which resembles the Dom phenotype (Pingault et al., 1998). Despite this critical role in development, no natural target genes of Sox10 have yet been identified.

Interestingly, Sox10 is highly expressed in neuronal structures in which the clustered $\beta 4, \alpha 3$, and $\alpha 5 \mathrm{nACh}$ receptor genes are also highly expressed. Furthermore, the $\alpha 3$ gene has been shown to be regulated by the POU domain protein Tst-1/Oct6/SCIP (Yang et al., 1994), a factor for which Sox10 has been shown to be an accessory protein (Kuhlbrodt et al., 1998a). Therefore, we 
investigated the possibility that Sox10 may participate in the transcriptional regulation of the $\beta 4$ and $\alpha 3$ subunit genes.

\section{MATERIALS AND METHODS}

Plasmids. The wild-type rat $\beta 4 /$ luciferase expression plasmid $\mathrm{pX1B} 4 \mathrm{FH}$, containing a $226 \mathrm{bp}$ FokI/HindIII fragment spanning nucleotides -89 to +137 , relative to the $\beta 4$ transcription initiation site, was described previously (Hu et al., 1994). A $2.1 \mathrm{~kb} H i n \mathrm{dIII} / \mathrm{SacI}$ fragment of the rat $\alpha 3$ genomic clone $\lambda$ RG518B (Boulter et al., 1990) [generously provided by Jim Boulter (University of California, Los Angeles, Los Angeles, CA)], containing nucleotides -2036 to +64 , relative to the $\alpha 3$ transcription start site, was subcloned into the promoterless luciferase expression vector pXP1 (Nordeen, 1988), yielding a wild-type $\alpha 3 /$ luciferase expression construct, pX1A3HS. All of the Sox10 expression constructs were kindly provided by Dr. Michael Wegner (Hamburg University, Hamburg, Germany) and are described in detail elsewhere (Kuhlbrodt et al., 1998a,b). The expression plasmid pCGS-SCIP, containing the SCIPcoding sequence inserted downstream of the cytomegalovirus (CMV) promoter (Monuki et al., 1993), was generously provided by Dr. Greg Lemke (The Salk Institute, San Diego, CA).

Site-directed mutagenesis. Site-directed mutagenesis of the wild-type $\beta 4 /$ luciferase construct $\mathrm{pX} 1 \mathrm{~B} 4 \mathrm{FH}$ was performed as described previously (Bigger et al., 1996) except that a different 5' primer (5'-GAC GGA TCC CTC TCA GAC CCT CCC CTC CCC TGT GGC ACC AGC GCA TCC CAA-3') was used.

Preparation of recombinant proteins. The T7-tag-Sox10 fusion protein construct pET28c/SX107.1.1. $\mathrm{N}$ was also a kind gift of Dr. Michael Wegner (Kuhlbrodt et al., 1998a). This fusion protein contains amino acids $89-466$ of the rat Sox10 protein fused in-frame with a T7-tag sequence. Expression and purification of T7-tag fusion protein were performed using a T7-tag monoclonal antibody purification kit (Novagen, Madison, WI).

Cell culture and transfections. HeLa, Neuro2A, and Rat2 cells were obtained from the American Type Culture Collection (Rockville, MD). Neuro2A cells (Klebe et al., 1970) were grown in minimal essential medium (Life Technologies, Gaithersburg, MD) supplemented with $10 \%$ fetal bovine serum (FBS; Sigma, St. Louis, MO). HeLa (Gey et al., 1952) and SN17 cells (Hammond et al., 1990) were maintained in DMEM supplemented with 10\% FBS. Sol8 cells (Daubas et al., 1988) were cultured in DMEM containing 20\% FBS and 0.5\% chicken embryo extract (Life Technologies). NIH3T3 cells (Jainchill et al., 1969) were grown in DMEM containing 10\% calf serum (Sigma). Rat2 cells (Topp, 1981) were grown in DMEM containing 5\% FBS. Pheochromocytoma 12 (PC12) cells (Greene and Tischler, 1976) were cultured and differentiated with nerve growth factor (Upstate Biotechnology, Lake Placid, NY) as described previously (Hu et al., 1994).

Neuro2A, SN17, Sol8, NIH3T3, and HeLa cells were transfected at $60 \%$ confluency in $60 \mathrm{~mm}$ dishes using a calcium phosphate method and a commercially available kit (5 Prime- 3 Prime, Boulder, CO). Cells were transfected with $5 \mu \mathrm{g}$ of test DNA (pX1B4FH or pX1A3HS), $5 \mu \mathrm{g}$ of effector DNA [the empty pCMV5 vector (Invitrogen, Carlsbad, CA), pCMVSox 10 constructs, or pCGS-SCIP], and $5 \mu \mathrm{g}$ of a $\beta$-galactosidase expression vector, pCH110 (Pharmacia, Piscataway, NJ ). In some cases, no effector DNA was included in the transfections. To test dose dependency, we transfected Neuro2A cells with either pX1B4FH or pX1A3HS and $1,2,4$, or $8 \mu \mathrm{g}$ of wild-type pCMVSox 10 expression plasmid. To insure that the calcium phosphate/DNA precipitates had equal amounts of DNA, we added appropriate quantities of pBluescript II SK DNA (Stratagene, La Jolla, CA) to each sample. Rat2 cells were transfected in $60 \mathrm{~mm}$ dishes at a density of $10^{5} \mathrm{cells} / \mathrm{ml}$ using $30 \mu \mathrm{l}$ of Lipofectamine (2 $\mathrm{mg} / \mathrm{ml}$; Life Technologies) and the same quantities of DNAs as described above. Forty-eight hours after transfection, cells were harvested and assayed for luciferase activity using a commercially available kit (Promega, Madison, WI) and an Autolumat LB953 luminometer (EG\&G Berthold, Gaithersburg, MD). All transfections were done a minimum of two times with two different preparations of plasmid DNAs. To correct for differences in transfection efficiencies between dishes, we normalized the luciferase activity in each sample to the $\beta$-galactosidase activity in the same sample, which was measured using a commercially available kit (Galacto-Light; Tropix, Bedford, MA).

Western blotting. Preparation of cell lysates and Western blotting were performed as described previously (Bigger et al., 1997). Anti-Sox10 antibody was a generous gift from Dr. Michael Wegner (Kuhlbrodt et al., 1998a) and was used at a 1:3000 dilution in Blotto.

Electrophoretic mobility shift assays. Electrophoretic mobility shift as- says were performed using either a ${ }^{32} \mathrm{P}$-labeled double-stranded $\beta 4$ oligonucleotide (see Fig. $5 A$, sequence) and $1 \mu \mathrm{g}$ of recombinant T7-tagSox10 protein or a ${ }^{32} \mathrm{P}$-labeled double-stranded CA box oligonucleotide (see Fig. $5 A$, sequence) and $3.5 \mu \mathrm{g}$ of rat brain nuclear extract [prepared as described previously (Hu et al., 1995)]. Reaction mixtures containing protein, binding buffer (10 mM HEPES, pH 8.0, $50 \mathrm{~mm} \mathrm{NaCl}, 5 \mathrm{~mm}$ $\mathrm{MgCl}_{2}, 2 \mathrm{~mm}$ DTT, $0.1 \mathrm{~mm}$ EDTA, and 5\% glycerol), and either $0.5 \mu \mathrm{g}$ (for T7-tag-Sox10) or $2 \mu \mathrm{g}$ (for nuclear extract) of poly(dI-dC) were preincubated for $5 \mathrm{~min}$ at room temperature (RT; for T7-tag-Sox10) or on ice (for nuclear extract) before the addition of $5 \mathrm{fmol}$ of the endlabeled probe. After addition of the probe, binding reactions were further incubated for $15 \mathrm{~min}$ at RT. For competition experiments, unlabeled double-stranded $\beta 4$ oligonucleotides or Sox oligonucleotide, containing a consensus binding site for Sox proteins (see Fig. $5 A$, sequence) (Kuhlbrodt et al., 1998a), were preincubated with the protein for 5 min before the addition of labeled oligonucleotides. Reaction mixtures were then electrophoresed through $6 \%$ native polyacrylamide gels. Radioactivity was detected by autoradiography of the dried gels.

\section{RESULTS}

\section{Cell type-specific activity of the $\beta 4$ promoter region}

We described previously the isolation and partial characterization of the $5^{\prime}$-flanking region of the rat $\beta 4$ subunit gene (Hu et al., 1994) and identified two transcriptional regulatory elements that are critical for $\beta 4$ promoter activity (Hu et al., 1995; Bigger et al., 1996). The regulatory elements, a CT box and a CA box, are located within a 226 bp FokI/HindIII fragment that possesses strong transcriptional activity (Fig. $1 A$ ) (Hu et al., 1995; Bigger et al., 1996). To determine whether the transcriptional activity is cell type dependent, we performed a series of transient transfection experiments using a variety of neuronal and non-neuronal cell lines. When neuronal cell lines were transfected with the $\beta 4 /$ luciferase construct pX1B4FH (Fig. 1A), significant luciferase activity was detected (Fig. $1 B$ ). In contrast, no significant activity was seen in extracts of transfected non-neuronal cell lines (Fig. $1 B)$. These data suggest that the transcriptional activity of $\mathrm{pX} 1 \mathrm{~B} 4 \mathrm{FH}$ is cell type specific. The $\alpha 3$ promoter region has been extensively characterized by Deneris and colleagues (Yang et al., 1994, 1995, 1997; McDonough and Deneris, 1997).

\section{Sox10 transactivates the neuronal nACh receptor $\beta 4$ and $\alpha 3$ subunit gene promoters in a cell type-specific manner}

Because the temporal and spatial patterns of expression of Sox10 partially overlap those of the $\beta 4$ and $\alpha 3$ subunit genes, we set out to investigate whether Sox10 can regulate the promoter activities of these genes. To determine whether Sox10 can transactivate the $\beta 4$ and $\alpha 3$ gene promoters, transfection experiments were performed in various cell lines with the $\beta 4$ or $\alpha 3$ promoter/luciferase reporter constructs alone or in combination with an expression construct in which the rat Sox10 gene is under the control of the CMV promoter (Fig. 2). To confirm that Sox10 expression was involved in transactivation, we also transfected the reporter constructs with the pCMV vector alone (devoid of the Sox10-coding sequence). The cell lines included two rodent neuroblastoma lines, SN17 and Neuro2A, two fibroblast cell lines, NIH3T3 and Rat2, and one mouse muscle cell line, Sol8.

Cotransfection of the $\beta 4$ (Fig. $2 A$ ) and $\alpha 3$ (Fig. $2 B$ ) reporter constructs with an "empty" pCMV vector had no effect on reporter gene expression in any of the cell types tested. However, when the $\beta 4$ and $\alpha 3$ reporters were cotransfected with Sox10, a dramatic transactivation of reporter gene activity was observed in Neuro2A and SN17 cells ( $\sim 20$ - to 30-fold induction over background) but not in the muscle or fibroblast cell lines (Fig. $2 A, B$ ). To confirm that Sox10 protein was synthesized in the transfected 


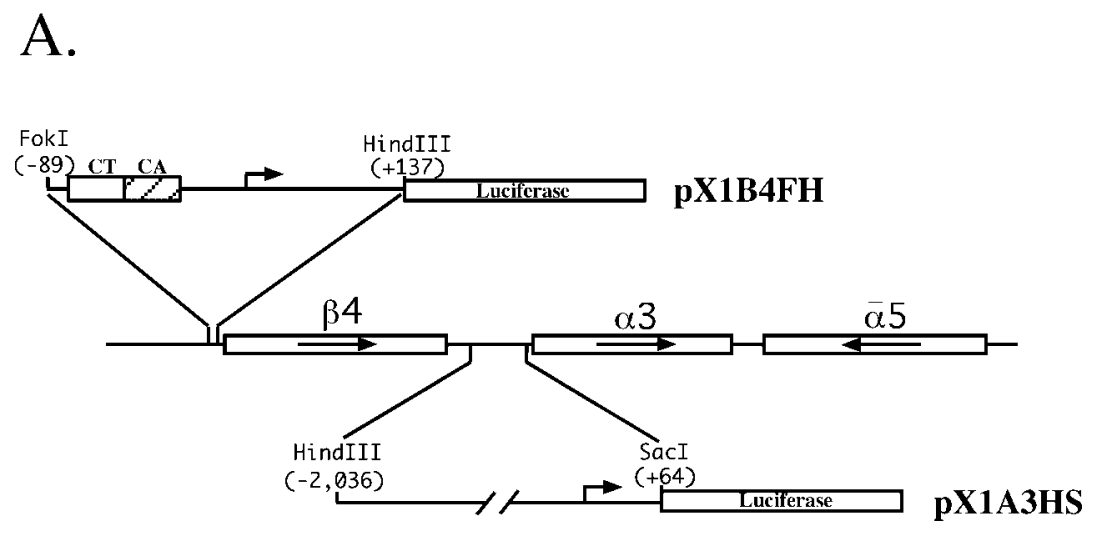

B.

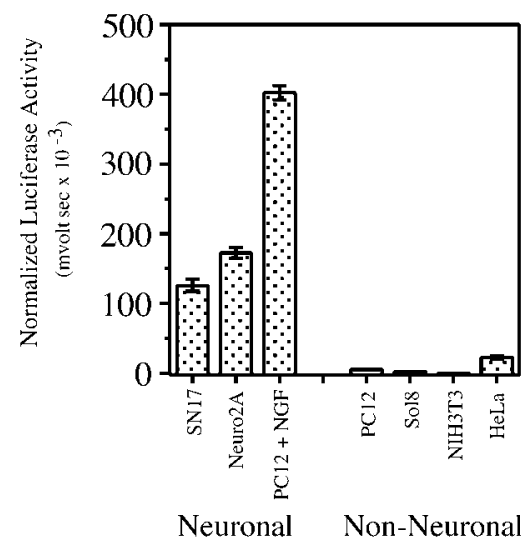

Figure 1. $A, \beta 4$ and $\alpha 3$ promoter/luciferase constructs. The genomic organization of the clustered nACh receptor subunit genes is presented. The straight arrows indicate directions of transcription. The $5^{\prime}$-flanking regions of the $\beta 4$ and $\alpha 3$ subunit genes were subcloned upstream of the coding sequence for luciferase to generate pX1B4FH and pX1A3HS, respectively. Numbers correspond to the positions of the $5^{\prime}$-most and $3^{\prime}$-most nucleotides of the fragments relative to the major transcription initiation sites (bent arrows). $B$, Cell type-specific activity of the $\beta 4$ promoter. Neuronal cell lines [SN17, Neuro2A, and nerve growth factor (NGF)-treated PC12] and non-neuronal cell lines (untreated PC12, Sol8 muscle, NIH3T3 fibroblast, and HeLa cervical carcinoma) were transiently transfected with pX1B4FH as described in Materials and Methods. Luciferase values were normalized to correct for differences in transfection efficiencies (see Materials and Methods). Error bars represent SDs.

cells, qualitative Western blot analysis was performed. As shown in Figure $2 C$, extracts of all five pCMVSox10-transfected cell lines had readily detectable levels of Sox10 protein, indicating that the lack of transactivation in the non-neuronal cell lines was most likely not caused by the lack of Sox10 protein. Furthermore, transactivation of the $\beta 4$ and $\alpha 3$ promoter/luciferase constructs by Sox10 occurs in a dose-dependent manner in both Neuro2A (Fig. 3) and SN17 (data not shown) cells. Taken together, these results indicate that Sox 10 can activate both the $\beta 4$ and $\alpha 3$ subunit gene promoters and does so in a neuron-specific manner.

\section{Domains of Sox10 required for its transactivation activity}

In the experiment described above rat Sox10 protein was used. It has been reported previously that rat Sox10 protein does not possess a transactivation activity of its own when tested in glial cells and using a synthetic promoter containing a TATA box and multiple Sox consensus binding sites (Kuhlbrodt et al., 1998a). In contrast, results of two reports on human SOX10 indicate the presence of a potent transactivation domain at the $\mathrm{C}$ terminal of the human protein (Kuhlbrodt et al., 1998b; Pusch et al., 1998). Interestingly, the data presented in Figure 2 demonstrate that in the context of neuronal cell lines, rat Sox10 does in fact possess transactivation activity. Therefore, to map the domains of rat Sox10 that are required for its ability to transactivate the $\beta 4$ and $\alpha 3$ promoters in neuronal cells, transfection experiments were performed using a number of Sox10 mutants in both the Neuro2A (Fig. 4) and in SN17 (data not shown) cell lines. Mutant Sox10 $\Delta$ N lacks the N-terminal 89 amino acids, whereas Sox10-HMG contains only the HMG domain of the protein (Fig. $4 A$ ). Four of the SOX10 mutations, WS029, MIC, 059, and 095 (Fig. 4A), were originally identified in patients with Waardenburg-Hirschsprung syndrome, a disease characterized by deafness, pigmentation defects, and aganglionic megacolon (Pingault et al., 1998). Mutant WS029 is a nonsense mutation that converts tyrosine 83 to a stop codon; MIC is also a nonsense mutation leading to a truncated protein of only 188 amino acids; mutant 059 lacks the last 106 amino acids as a consequence of a deletion of two nucleotides at position 1076 resulting in a frameshift (the frameshift creates a sequence of 40 unrelated amino acids at the $\mathrm{C}$ terminal of the protein); and mutant 095 carries an insertion of six nucleotides between positions 482 and 483 leading to the addition of a leucine and an arginine into the HMG box (the open reading frame remains intact). Each of these four mutations observed in patients with Waardenburg-Hirschsprung syndrome was subsequently introduced into the rat Sox10 cDNA (Kuhlbrodt et al., 1998b). The transactivation data indicate that only wild-type Sox10 and mutant 059 are capable of significantly transactivating the $\beta 4$ and $\alpha 3$ promoters (Fig. 4). The fact that mutant 095 did not transactivate either the $\beta 4$ or $\alpha 3$ promoter provides evidence that an intact HMG box is required for Sox10 function. However, sequences in addition to the HMG box are necessary for transactivation because Sox10-HMG, which contains just the HMG domain, also failed to activate either promoter. Similar to Sox10-HMG, Sox $10 \Delta \mathrm{N}$ failed in this assay, suggesting that the extreme $\mathrm{N}$-terminal domain of rat Sox10 is required for its transcriptional activity. Furthermore, mutant MIC did not transactivate either $\mathrm{nACh}$ receptor gene promoter, indicating that the central and the $\mathrm{C}$-terminal portions of the protein are required for Sox10 activity. However, the 106 amino acids located at the extreme $\mathrm{C}$ terminal do not appear to be critical for Sox10 function because mutant 059 activated both promoters to levels similar to those of wildtype Sox10. Although we cannot formally exclude the slight possibility that mutants Sox10 $\Delta$ N, MIC, WS029, Sox10-HMG, or 095 failed to transactivate the $\beta 4$ promoter in Neuro2A cells because they were either not expressed to a sufficient extent or not properly translocated to the nucleus, the data presented above strongly suggest that the N-terminal 89 amino acids, the HMG domain, and amino acids 189-360 are necessary for the transactivation function of Sox10.

\section{Sox10 directly interacts with the $\beta 4$ promoter region}

As described above, the inability of mutant 095 to transactivate the $\beta 4$ and $\alpha 3$ promoters indicates that an intact HMG domain is required for Sox10 function. The fact that the HMG box mediates protein-DNA interactions (Kuhlbrodt et al., 1998a), coupled with the observation that mutant 095 is unable to bind DNA (Kuhlbrodt et al., 1998b), suggests that Sox10 must bind to DNA to 
A.

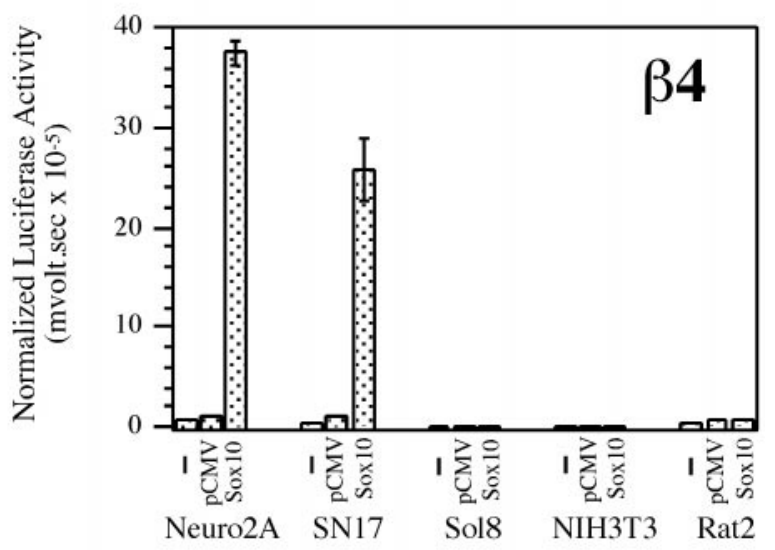

B.

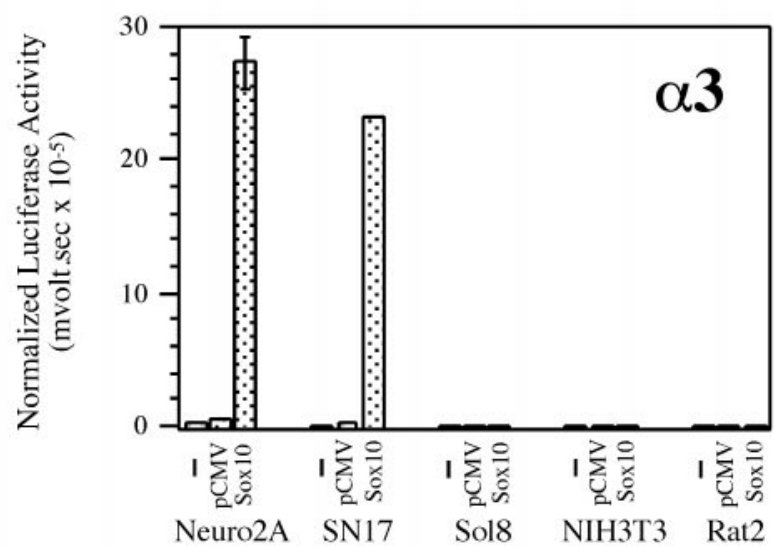

C.

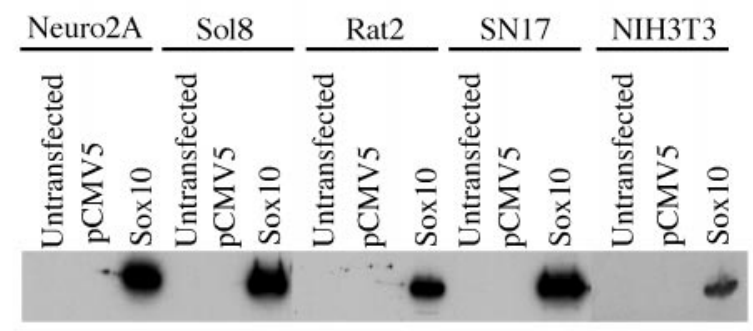

Figure 2. Sox10 transactivates the $\beta 4$ and $\alpha 3$ gene promoters in a cell type-specific manner. $A, B$, The $\beta 4 /$ luciferase construct pX1B4FH $(A)$ and the $\alpha 3 /$ luciferase construct pX1A3HS $(B)$ were transiently transfected into neuronal (Neuro2A and SN17) and non-neuronal (Sol8 muscle, NIH3T3, and Rat2 fibroblast) cell lines either alone (-) or with pCMV5 ( $p C M V)$ or pCMVSox10 (Sox10). Luciferase values were normalized to $\beta$-galactosidase expression as driven by the SV40 promoter. Error bars represent SDs. C, Qualitative Western blot analysis of transfected cells is shown. Cell extracts were prepared from untransfected cells or cells transfected with pCMV5 or pCMVSox10. For a given cell line, equivalent amounts of protein for each condition were analyzed by SDS-PAGE. After SDS-PAGE, Western blot analysis was done using anti-Sox10 antibody to demonstrate Sox10 expression in pCMVSox10transfected cells.

effect transactivation. No consensus binding site for Sox10 has yet been identified for any gene. However, to demonstrate the ability of Sox10 to bind to DNA, Kuhlbrodt et al. (1998a) used a synthetic oligonucleotide with a sequence that is recognized by several members of the Sox family (van de Wetering et al., 1993) in electrophoretic mobility shift assays. Although there are two
A.

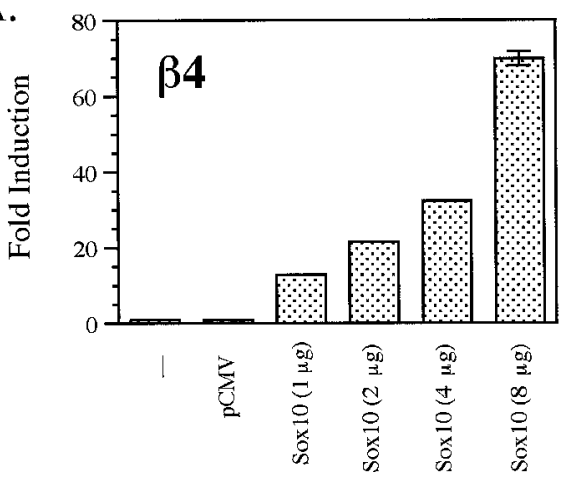

B.

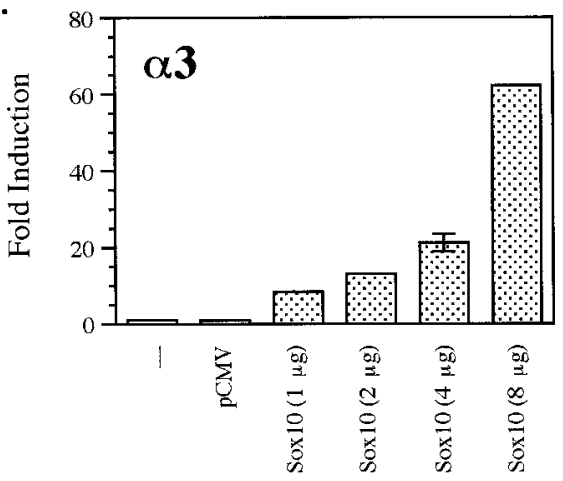

Figure 3. Dose-dependent activation of the $\beta 4$ and $\alpha 3$ promoters by Sox10. The $\beta 4 /$ luciferase construct pX1B4FH $(A)$ and the $\alpha 3 /$ luciferase construct pX1A3HS $(B)$ were cotransfected with pCMVSox10 $(1,2,4$, and $8 \mu \mathrm{g}$ ) in Neuro2A cells. Luciferase values were normalized to $\beta$-galactosidase expression as driven by the SV40 promoter. Fold induction was calculated relative to the normalized luciferase activity obtained by transfecting pX1B4FH or pX1A3HS alone. Error bars represent SDs.

classic Sox consensus binding sites, C(T/A)TTTG(T/A)(T/A) (Pevny and Lovell-Badge, 1997; Wegner, 1999), present in the promoter of $\alpha 3$ at positions -1275 and -1284 relative to the major transcription start site (Yang et al., 1994), this consensus sequence is not present in the 226 bp FokI/HindIII $\beta 4$ promoter fragment used in the transfection experiments described above. Therefore, to demonstrate that Sox10 interacts directly with the $\beta 4$ promoter, electrophoretic mobility shift assays were done using a double-stranded oligonucleotide encompassing the CT and $\mathrm{CA}$ boxes of the $\beta 4$ promoter region as the probe (Fig. $5 A$ ). As discussed previously, these two regulatory elements are critical for $\beta 4$ promoter activity. Incubation of recombinant T7-tagSox10 fusion protein with radioactively labeled $\beta 4$ oligonucleotide led to the formation of a single specific Sox10/DNA complex (Fig. 5B). An unlabeled oligonucleotide corresponding to the consensus Sox-binding site also competed for binding to Sox10, but the competition was not complete (i.e., even at 500-fold molar excess of the Sox oligonucleotide, there was still Sox $10 / \beta 4$ complex formation; Fig. $5 B$ ). This may reflect differences in the affinity of Sox10 for the two sites. In an attempt to localize the Sox10-binding site further, competition experiments were done using oligonucleotides containing either the CT box or the CA box (Fig. $5 A$ ). The CT box failed to compete for binding to Sox10, whereas the CA box competed as well as the $\beta 4$ oligonucleotide (Fig. $5 B$ ). When a CA box oligonucleotide mutated in six positions (Fig. $5 A$ ) was used as a competitor, no competition was seen (Fig. $5 B$ ). These data suggest that a region of the $\beta 4$ promoter 
A.

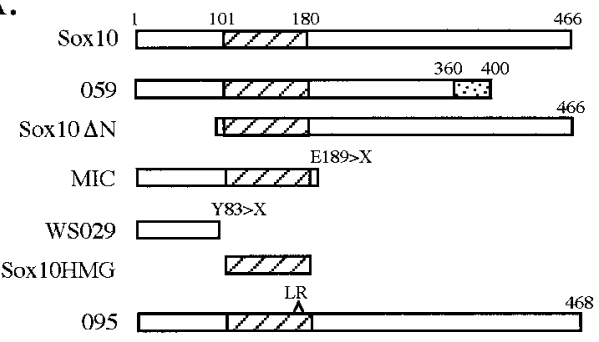

B.

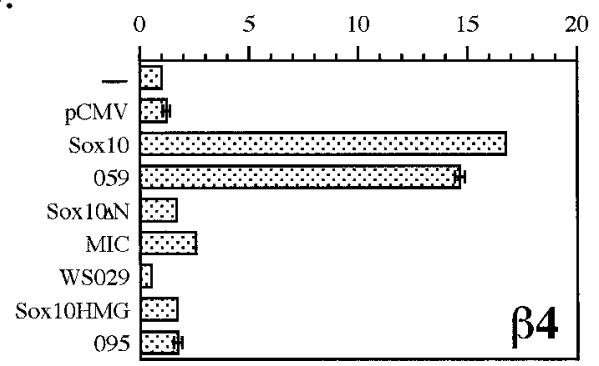

C.

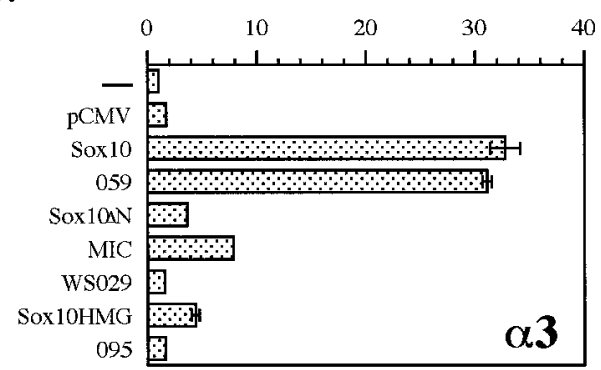

Figure 4. Protein domains of Sox10 required for its transcriptional activity. $A$, Schematic representations of the Sox10 expression constructs used for transfection analysis (see Results for details) are shown. The hatched box represents the HMG domain in each construct. The dotted box in mutant 059 represents 40 unrelated amino acids created by a frameshift (see Results). $B, C$, Neuro2A cells were transfected with the $\beta 4 /$ luciferase construct $\mathrm{pX} 1 \mathrm{~B} 4 \mathrm{FH}(B)$ or the $\alpha 3 /$ luciferase construct pX1A3HS $(C)$ either alone $(-)$ or with pCMV5, wild-type Sox10, or one of the Sox 10 mutant constructs as indicated. Fold induction was calculated as described in Figure 3.

that overlaps the CA box is involved in direct interactions with Sox10. As an initial attempt to determine whether Sox10/ $\beta 4$ interactions may occur in a more physiological context, electrophoretic mobility shift assays were performed using radioactively labeled CA box as a probe and nuclear extract prepared from adult rat brain as a protein source. As shown in Figure $5 C$, incubation of the $\mathrm{CA}$ box probe with brain nuclear extract resulted in the formation of several DNA-protein complexes. Formation of these complexes was competed by unlabeled CA box and by unlabeled consensus Sox-binding site oligonucleotides but not by the mutated CA box oligonucleotide (Fig. $5 C$ ). These data are consistent with the electrophoretic mobility shift results obtained using purified Sox10 (Fig. $5 B$ ) and provide further evidence of direct interactions between the $\beta 4$ promoter and Sox 10 .

To test the functional significance of these interactions, the same point mutations were introduced into a $\beta 4$ promoter/luciferase construct and subsequently used in transfection experiments. As shown in Figure $5 D$, Sox10 transactivation of the mutated promoter was significantly less than that of the wild-type promoter. Taken together, these data strongly suggest that Sox10 directly interacts with the $\beta 4$ promoter in a functionally relevant manner.

\section{Sox10 and Tst-1/Oct6/SCIP do not transactivate the nACh receptor $\beta 4$ or $\alpha 3$ subunit gene promoters synergistically in Neuro2A or SN17 cells}

Sox proteins have been proposed to function as cell type-specific accessory proteins for POU domain factors (Yuan et al., 1995). Indeed, the initial characterization of Sox10 showed that it can function synergistically with the POU domain protein Tst-1/Oct6/ SCIP to activate transcription in glial cells (Kuhlbrodt et al., 1998a). This is particularly relevant to nACh receptor gene expression because it has been demonstrated that Tst-1/Oct6/SCIP is capable of activating the $\alpha 3$ promoter in vitro (Yang et al., 1994). Interestingly, activation of the $\alpha 3$ promoter by Tst-1/Oct6/ SCIP appears to be indirect, because it occurs independently of the Tst-1/Oct6/SCIP-binding sites (Fyodorov and Deneris, 1996). We therefore tested, first, the ability of Tst-1/Oct6/SCIP to activate the $\beta 4$ promoter and, second, the possible synergy of Sox10 and Tst-1/Oct6/SCIP in transactivating the $\beta 4$ and $\alpha 3$ promoters. As shown in Figure $6 A$, Tst-1/Oct6/SCIP activated the $\beta 4$ promoter $\sim 35$-fold in SN17 cells and 20-fold in Neuro2A cells. Little or no transactivation was detected in Sol8 muscle cells or in the fibroblast cell line NIH3T3. Thus, both the $\beta 4$ and $\alpha 3$ promoters can be activated by Tst-1/Oct6/SCIP. Moreover, the transactivation activity of Tst-1/Oct6/SCIP on the $\beta 4$ promoter is cell type specific. As also shown in Figure 6, cotransfection of SN17 cells with Tst-1/Oct6/SCIP and Sox10 did not lead to an additive or a synergistic effect on $\beta 4$ or $\alpha 3$ promoter activities, with the activation being comparable with that seen with Sox10 alone. Similar results were observed in Neuro2A cells as well (data not shown). This raises the possibility, then, that the synergistic interaction of Tst-1/Oct6/SCIP and Sox10 seen by Kuhlbrodt et al. (1998a) may be glial cell specific and that it does not occur in neuronal cells. Another possibility is that activation by Sox10 was at a saturated level in the above experiments, and therefore, no synergy would occur under such conditions. However, dose-response experiments performed using lower amounts of both Sox10 and Tst-1/ Oct6/SCIP also failed to uncover any synergistic effects (data not shown).

\section{DISCUSSION}

Sox10 belongs to the Sox family of transcription factors, members of which are characterized by the presence of a DNA-binding domain, an HMG box that is highly similar to the HMG domain of the mammalian sex determination factor Sry (Pevny and Lovell-Badge, 1997; Wegner, 1999). Sox proteins play important roles during a number of developmental processes such as sex determination, chondrogenesis, neurogenesis, and lens formation (Wegner, 1999). Sox10 has been proposed to be a regulator of neural crest development (Herbarth et al., 1998; Southard-Smith et al., 1998). Dom mice, which carry a Sox10 frameshift mutation, are characterized by several neural crest defects. Heterozygotes have pigmentation abnormalities and suffer from aganglionic megacolon; homozygotes have significant losses of neurons and glia in the PNS, and in addition, their entire enteric nervous system is lacking (Herbarth et al., 1998; Southard-Smith et al., 1998). Patients with Waardenburg-Hirschsprung syndrome carry mutations in one of the alleles of SOX10 and display phenotypic abnormalities similar to those found in Dom mice (Pingault et al., 

A.

$\begin{array}{rr}\text { B4: } & \frac{\text { CT Box }}{\text { ACCCTCCCTCCCTGTAACTCCACCCCTTCCCCA }} \\ \text { CT Box: } & \text { ACCCTCCCCTCCCTGTAA } \\ \text { CA Box: } & \text { TGTAACTCCACCCCTTCCCCAGTTCC } \\ \text { Mutant CA Box: } & \text { TGTGGCACCAGCGCATCCCCAGTTCC } \\ \text { Sox: } & \text { GATCCGCGCCTTTTTCTCCCCA }\end{array}$

B.
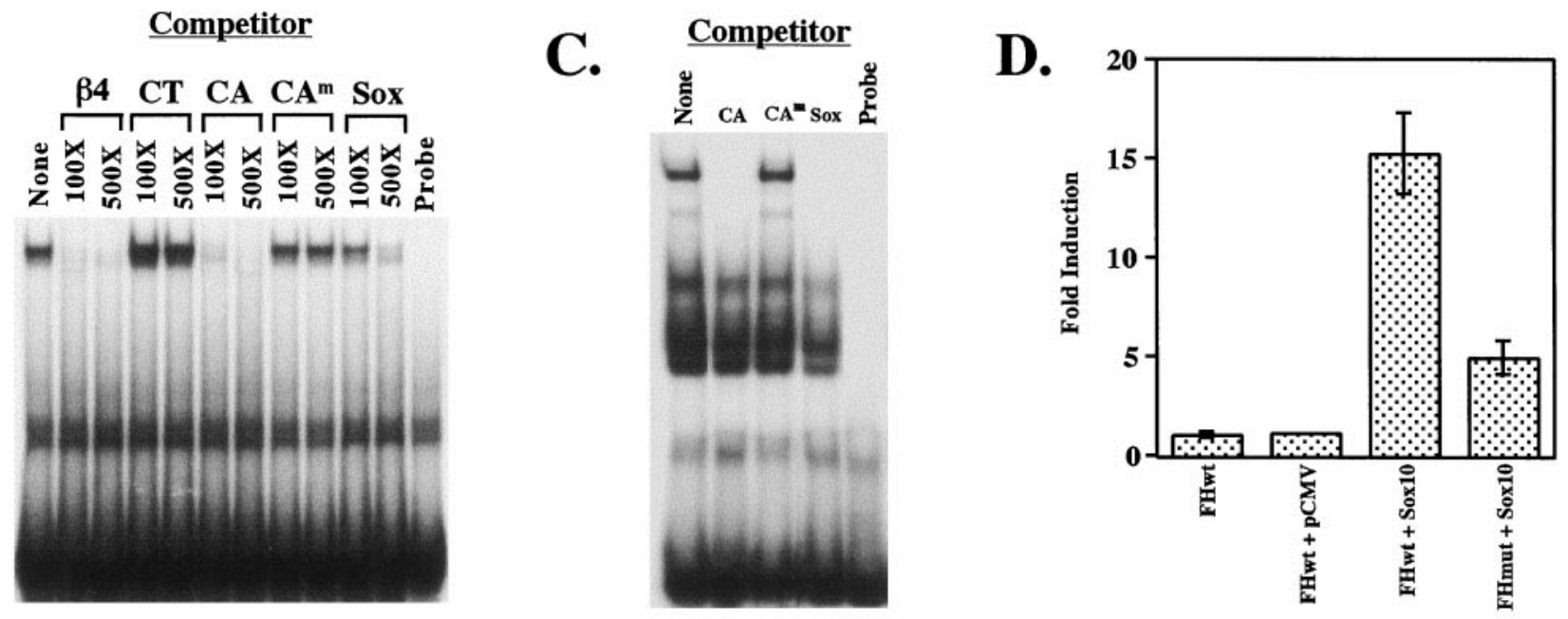

Figure 5. Direct interactions between Sox10 and the $\beta 4$ promoter region are functionally relevant. $A$, Sequences of the oligonucleotides used in electrophoretic mobility shift assays are shown. Mutations in the CA box oligonucleotide are underlined. The sequence of an oligonucleotide corresponding to a consensus binding site for Sox proteins (Pevny and Lovell-Badge, 1997) is also shown. B, Electrophoretic mobility shift assays were performed using $5 \mathrm{fmol}$ of a radiolabeled oligonucleotide ( $\beta 4$ in $A$ ) corresponding to nucleotides -82 to -48 of the $\beta 4$ gene and $1 \mu \mathrm{g}$ of T7-tag-Sox 10 protein. The left lane shows DNA-protein complex formation in the absence of competitors. Competition experiments were performed using 100- and 500 -fold molar excesses of competitor oligonucleotides (either unlabeled wild-type or mutated $\beta 4$ oligonucleotides or the consensus Sox-binding site oligonucleotide). The right lane contains unbound $\beta 4$ probe in the absence of Sox10 protein. $C$, Electrophoretic mobility shift assays were performed using $5 \mathrm{fmol}$ of a radiolabeled oligonucleotide $(C A B o x$ in $A)$ and $3.5 \mu \mathrm{g}$ of rat brain nuclear extract. The left lane shows DNA-protein complex formation in the absence of competitors. Competition experiments were performed using 100-fold molar excess of competitor oligonucleotides (either unlabeled wild-type or mutated CA box oligonucleotides or the consensus Sox-binding site oligonucleotide). The right lane contains unbound CA box probe in the absence of protein. $D$, The mutations shown in $A$ (Mutant CA Box) were introduced into the $\beta 4 /$ luciferase construct $\mathrm{pX} 1 \mathrm{~B} 4 \mathrm{FH}$ to create $\mathrm{pX} 1 \mathrm{~B} 4 \mathrm{FHm}$ (m) Wild-type pX1B4FH (FHwt) and pX1B4FHmut (FHmut) were cotransfected into Neuro2A cells with pCMVSox10. As controls, wild-type pX1B4FH was also transfected either alone $(F H w t)$ or with pCMV5 $(p C M V)$. Luciferase values were normalized to $\beta$-galactosidase expression as driven by the SV40 promoter. Fold induction was calculated relative to the normalized luciferase activity obtained by transfecting wild-type pX1B4FH alone. Error bars represent SDs. $C A^{m}$, Mutant CA box.

1998). Despite the well-characterized phenotypes resulting from mutations in Sox10, no natural target genes for this factor have been documented.

The $\alpha 3$ and $\beta 4$ subunits, together with $\alpha 5$, form the predominant $\mathrm{nACh}$ receptor subtype expressed in the PNS. Because these three genes are tightly clustered genomically, it is possible that they are subject to coordinate regulation. In agreement with this idea, Sp1 has been shown to transactivate these three genes (Yang et al., 1995; Bigger et al., 1996, 1997; Campos-Caro et al., 1999). We demonstrated previously that in addition to $\mathrm{Sp} 1$, the $\beta 4$ promoter can be transactivated by another member of the Sp family, Sp3 (Bigger et al., 1997). Moreover, it appears that the transactivation potentials of Sp1 and Sp3 are differentially regulated by another protein capable of interacting with the $\beta 4$ promoter, hnRNP K (Du et al., 1998). Deneris and colleagues identified a PC12 cell-specific enhancer, $\beta 43^{\prime}$, in the $\beta 4 / \alpha 3$ intergenic region that is capable of activating transcription from the $\alpha 3$ and $\beta 4$ subunit gene promoters (McDonough and Deneris, 1997). A novel ETS-domain protein, Pet-1, can transactivate this enhancer in a cell type-specific manner (Fyodorov et al., 1998). However, the $\beta 43^{\prime}$ enhancer is not sufficient to direct reporter gene expression in the PNS, where $\alpha 3$ and $\beta 4$ are expressed, as judged by transgenic analysis (McDonough and Deneris, 1997). Deneris and colleagues have also demonstrated that the promoter of $\alpha 3$ can be transactivated by a POU domain protein, Tst-1/Oct6/ SCIP (Yang et al., 1994). In addition to regulation by Tst-1/Oct6/ SCIP, $\alpha 3$ can be regulated by another class of POU domain proteins, Brn-3. Although Brn-3a activates the $\alpha 3$ promoter, Brn-3b and Brn-3c repress it (Milton et al., 1996). The $\beta 4$ promoter appears to be unaffected by Brn-3 proteins (Milton et al., 1996). Transactivation of the $\alpha 3$ promoter by Tst-1/Oct6/SCIP was shown to be independent of the Tst-1/Oct6/SCIP DNAbinding sites, leading to the hypothesis that the observed effect is a consequence of protein-protein interactions (Yang et al., 1994). Interestingly, it appears that POU domain proteins can synergize and in some cases directly interact with Sox proteins (Yuan et al., 1995; Ambrosetti et al., 1997; Kuhlbrodt et al., 1998a,b). Tst-1/ Oct6/SCIP can synergistically activate transcription with Sox10 (Kuhlbrodt et al., 1998a), making Sox10 a potential candidate for the regulation of $\mathrm{nACh}$ receptor gene expression. Furthermore, the expression patterns of Sox10, $\alpha 3$, and $\beta 4$ spatially and temporally overlap in the developing nervous system (Zoli et al., 1995; Kuhlbrodt et al., 1998a). These observations prompted us to investigate whether Sox10 can regulate the $\alpha 3$ and $\beta 4$ promoters. 
A.

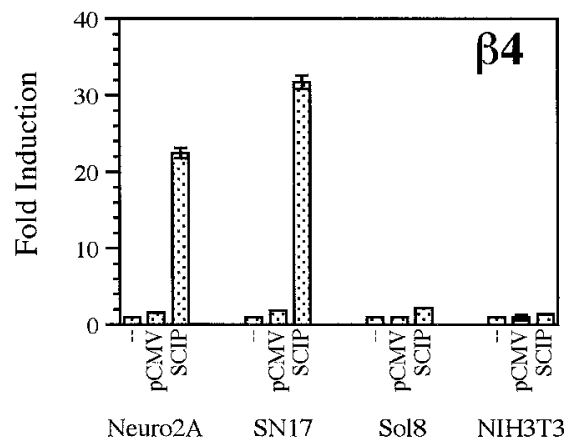

B.

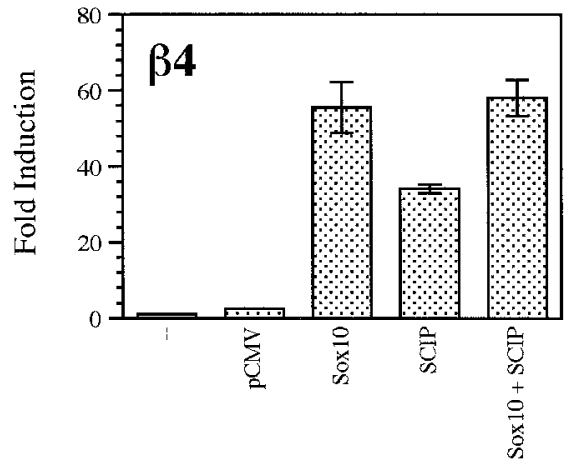

C.

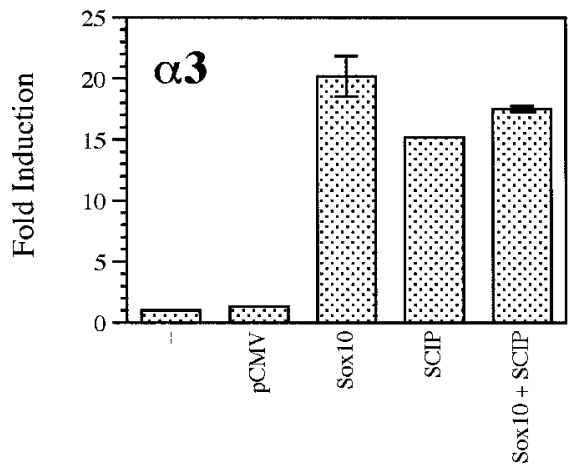

Figure 6. $A$, Tst-1/Oct6/SCIP transactivates the $\beta 4$ gene promoter in a cell type-specific manner. The $\beta 4 /$ luciferase construct $\mathrm{pX} 1 \mathrm{~B} 4 \mathrm{FH}$ was transfected into neuronal cell lines (Neuro2A and SN17) and nonneuronal cell lines (Sol8 muscle and NIH3T3 fibroblast) either alone (-) or with pCMV5 $(p C M V)$ or pCGS-SCIP $(S C I P)$. Fold induction was calculated as described in Figure 3. B, C, Tst-1/Oct6/SCIP and Sox10 do not transactivate the $\beta 4$ or $\alpha 3$ gene promoters additively or synergistically. SN17 cells were transfected with the $\beta 4 /$ luciferase construct $\mathrm{pX} 1 \mathrm{~B} 4 \mathrm{FH}$ $(B)$ or the $\alpha 3 /$ luciferase construct pX1A3HS $(C)$ either alone (-), with pCMV5 ( $p C M V)$, or with expression constructs for Sox10 and Tst-1/ Oct6/SCIP (SCIP) individually and together. Fold induction was calculated as described above.

The results presented here indicate that rat Sox10 can, by itself, significantly transactivate the $\alpha 3$ and $\beta 4$ promoters in neuronal cell lines but has no effect on the activity of these promoters in non-neuronal cells. Our data are in contrast to the results of Kuhlbrodt et al. (1998a) who were unable to detect any autonomous transactivation activity of rat Sox10 in glial cells either on an artificial promoter containing Sox-binding sites or in a heterologous system in which Sox10 was fused to the GAL4 DNAbinding domain and subsequently cotransfected with a reporter containing GAL4 DNA-binding sites (Kuhlbrodt et al., 1998a). Instead, Sox10 was able to function as a transactivator only in synergy with other transcription factors such as Tst-1/Oct6/SCIP or Pax3 (Kuhlbrodt et al., 1998a). It is possible, then, that the transcriptional activity of rat Sox10 observed in neuronal cells results from it synergizing with endogenous transcription factors present in those cells. On the other hand, it is possible that the transactivation domain of rat Sox10 is masked in glial cells but is accessible in other cell types, such as neurons. It is important to note that human SOX10 does possess a strong transactivation domain in its $\mathrm{C}$ terminal as assayed in the GAL4 system in COS cells (Pusch et al., 1998). The C-terminal domains of rat and human Sox10 are virtually identical in this region, with only one amino acid difference occurring at residue 415 (Pusch et al., 1998).

To determine which regions of Sox10 are important for its ability to transactivate the $\alpha 3$ and $\beta 4$ promoters in neuronal cells, we used a number of mutant Sox10 constructs. Our results indicate that the C-terminal 106 residues of rat Sox10 are dispensable for its activity in neuronal cells, suggesting that the C-terminal of rat Sox10 does not contain a transactivation domain in the context of neuronal cell lines. The basis for the functional differences between the $\mathrm{C}$-terminal domains of human and rodent Sox10 remains to be elucidated. An intact $\mathrm{HMG}$ domain is required for Sox10's transactivation activity; however, this domain alone is not sufficient because a mutant Sox10 consisting of just the HMG domain proved to be inactive. In addition to the HMG domain, the $\mathrm{N}$ terminal of Sox10 is absolutely necessary, but again not sufficient, for its activity, and the central part of the protein up to amino acid 360 is required as well. Taken together, these data suggest that to activate the $\alpha 3$ and $\beta 4$ promoters, Sox 10 must bind DNA. Preferred binding sites for Sox10 have not been reported; however, Sox10 has been demonstrated to bind to a Sox protein consensus site (Kuhlbrodt et al., 1998a). Sequence analysis of the promoter regions of $\alpha 3$ and $\beta 4$ revealed that the $\alpha 3$ promoter contains two consensus Sox-binding sites, whereas such elements were not found in the $\beta 4$ promoter. However, we demonstrated that Sox10 can specifically interact with an oligonucleotide containing the $\mathrm{CT}$ and $\mathrm{CA}$ elements of the $\beta 4$ promoter. These elements have been shown to be critical for $\beta 4$ promoter activity (Hu et al., 1995; Bigger et al., 1996). Interestingly, it appears that the affinity of Sox10 for this region of the $\beta 4$ promoter is higher than its affinity for the Sox consensus site.

As mentioned above, Sox10 can act synergistically with Tst-1/ Oct6/SCIP (Kuhlbrodt et al., 1998a), a factor that can transactivate the $\alpha 3$ promoter (Yang et al., 1994). We extended these observations to show that Tst-1/Oct6/SCIP is able to transactivate the $\beta 4$ promoter in a neuron-specific manner as well. Because the region of the $\beta 4$ promoter used does not contain binding sites for POU domain proteins, we suggest that, analogous to $\alpha 3$ activation (Yang et al., 1994), Tst-1/Oct6/SCIP may be able to regulate the $\beta 4$ promoter via interactions with other transcription factors. A similar mechanism has been proposed for the repression of the myelin $\mathrm{P}_{0}$ promoter by Tst-1/Oct6/SCIP (Monuki et al., 1990). We investigated the possibility that Tst-1/Oct6/SCIP can transactivate $\mathrm{nACh}$ receptor gene expression via functional interactions with Sox10 but were unable to detect any synergy between the two factors. There are several possibilities for this phenomenon. It has been demonstrated previously that synergistic interactions between Sox and POU domain proteins, such as those between Sox 2 and Oct3, Sox10 and Tst-1/Oct6/SCIP, and Sox11 (and similarly Sox4) and Brn-1 and Brn-2, require binding of the respective factors to adjacent sites on DNA (Ambrosetti et al., 1997; Kuhlbrodt et al., 1998a,b). Therefore, because the $\alpha 3$ and 
$\beta 4$ promoters do not contain binding elements for POU domain proteins, Tst-1/Oct6/SCIP and Sox10 may be unable to interact functionally. However, the HMG2 protein can synergistically interact with the Oct factors in the absence of DNA-binding sites for the former (Zwilling et al., 1995). This observation raises the possibility that the functional interactions between POU and HMG domain proteins, such as the Sox family members, might occur in a cell type-specific manner.

In summary, we have identified the nACh receptor $\beta 4$ and $\alpha 3$ subunit genes as natural target genes of rat Sox10. Furthermore, we have shown that Sox10 transactivates the $\beta 4$ and $\alpha 3$ gene promoters in a neuron-specific manner. In addition, we have shown that, similar to the $\alpha 3$ promoter, the POU domain protein Tst-1/Oct6/SCIP can transactivate the $\beta 4$ gene promoter in a neuron-specific manner. However, no synergistic effect of Sox10 and Tst-1/Oct6/SCIP was observed in the neuronal cell lines tested. On the basis of these results, we hypothesize that Sox10 is a crucial regulatory factor involved in the neuron-specific expression of the $\beta 4$ and $\alpha 3$ subunit genes.

\section{REFERENCES}

Ambrosetti D-C, Basilico C, Dailey L (1997) Synergistic activation of the fibroblast growth factor 4 enhancer by Sox 2 and Oct-3 depends on protein-protein interactions facilitated by a specific spatial arrangement of factor binding sites. Mol Cell Biol 17:6321-6329.

Bigger CB, Casanova EA, Gardner PD (1996) Transcriptional regulation of neuronal nicotinic acetylcholine receptor genes: functional interactions between $\mathrm{Sp} 1$ and the rat $\beta 4$ subunit gene promoter. J Biol Chem 271:32842-32848.

Bigger CB, Melnikova IN, Gardner PD (1997) Sp1 and Sp3 regulate expression of the neuronal nicotinic acetylcholine receptor $\beta 4$ subunit gene. J Biol Chem 272:25976-25982.

Bondurand N, Kobetz A, Pingault V, Lemort N, Encha-Razavi F, Couly G, Goerich DE, Wegner M, Abitbol M, Goossens M (1998) Expression of the SOX10 gene during human development. FEBS Lett 432:168-172.

Boulter J, O'Shea-Greenfield A, Duvoisin RM, Connolly JG, Wada E, Jensen A, Gardner PD, Ballivet M, Deneris ES, McKinnon D, Heinemann S, Patrick J (1990) $\alpha 3, \alpha 5$, $\beta 4$ : three members of the rat neuronal nicotinic acetylcholine receptor-related gene family form a gene cluster. J Biol Chem 265:4472-4482.

Boyd RT (1994) Sequencing and promoter analysis of the genomic region between the rat neuronal nicotinic acetylcholine receptor $\beta 4$ and $\alpha 3$ genes. J Neurobiol 25:960-973.

Boyd RT (1997) The molecular biology of neuronal nicotinic acetylcholine receptors. Crit Rev Toxicol 27:299-318.

Campos-Caro A, Carrasco-Serrano C, Valor LM, Viniegra S, Ballesta JJ, Criado M (1999) Multiple functional Sp1 domains in the minimal promoter region of the neuronal nicotinic receptor $\alpha 5$ subunit gene. J Biol Chem 274:4693-4701.

Conroy WG, Berg DK (1995) Neurons can maintain multiple classes of nicotinic acetylcholine receptors distinguished by different subunit combinations. J Biol Chem 270:4424-4431.

Conroy WG, Vernallis AB, Berg DK (1993) The $\alpha 5$ gene product assembles with multiple acetylcholine receptor subunits to form distinctive receptor subtypes in brain. Neuron 9:679-691.

Daubas P, Klarsfeld A, Garner I, Pinset C, Cox R, Buckingham M (1988) Functional activity of the two promoters of the myosin alkali light chain gene in primary muscle cell cultures: comparison with other muscle gene promoters and other culture systems. Nucleic Acids Res 16:1251-1270.

Denny P, Swift S, Brand N, Dabhade N, Barton P, Ashworth A (1992) A conserved family of genes related to the testis determining gene, SRY. Nucleic Acids Res 20:2887.

Du Q, Tomkinson AE, Gardner PD (1997) Transcriptional regulation of neuronal nicotinic acetylcholine receptor genes: a possible role for the DNA-binding protein Pur $\alpha$. J Biol Chem 272:14990-14995.

Du Q, Melnikova IN, Gardner PD (1998) Differential effects of hnRNP $\mathrm{K}$ on Sp1- and Sp3-mediated transcriptional activation of a neuronal nicotinic acetylcholine receptor promoter. J Biol Chem 273:19877-19883.
Elgoyhen AB, Johnson DS, Boulter J, Vetter DE, Heinemann S (1994) $\alpha 9$ : an acetylcholine receptor with novel pharmacological properties expressed in rat cochlear hair cells. Cell 79:705-715.

Fornasari D, Battaglioli E, Flora A, Terzano S, Clementi F (1997) Structural and functional characterization of the human $\alpha 3$ nicotinic subunit gene promoter. Mol Pharmacol 51:250-261.

Fyodorov D, Deneris E (1996) The POU domain of SCIP/Tst-1/Oct-6 is sufficient for activation of an acetylcholine receptor promoter. Mol Cell Biol 16:5004-5014.

Fyodorov D, Nelson T, Deneris E (1998) Pet-1, a novel ETS domain factor that can activate neuronal nAChR gene transcription. J Neurobiol 34:151-163.

Gerzanich V, Kuryatov A, Anand R, Lindstrom J (1997) “Orphan” $\alpha 6$ nicotinic AChR subunit can form a functional heteromeric acetylcholine receptor. Mol Pharmacol 51:320-327.

Gey GO, Coffman WD, Kubicek MT (1952) Tissue culture studies of the proliferative capacity of cervical carcinoma and normal epithelium. Cancer Res 12:264-265.

Greene LA, Tischler AS (1976) Establishment of a noradrenergic clonal line of rat adrenal pheochromocytoma cells which respond to nerve growth factor. Proc Natl Acad Sci USA 73:2424-2428.

Gubbay J, Collignon J, Koopman P, Capel B, Economou A, Münsterberg A, Vivian N, Goodfellow P, Lovell-Badge R (1990) A gene mapping to the sex-determining region of the mouse $\mathrm{Y}$ chromosome is a member of a novel family of embryonically expressed genes. Nature 346:245-250.

Hammond DN, Lee HJ, Tonsgard JH, Wainer BH (1990) Development and Characterization of clonal cell lines derived from septal cholinergic neurons. Brain Res 512:190-200.

Herbarth B, Pingault V, Bondurand N, Kuhlbrodt K, HermansBorgmeyer I, Puliti A, Lemort N, Goossens M, Wegner M (1998) Mutation of the Sry-related Sox10 gene in Dominant megacolon, a mouse model for human Hirschsprung disease. Proc Natl Acad Sci USA 95:5161-5165.

Hu M, Whiting Theobald NL, Gardner PD (1994) Nerve growth factor increases the transcriptional activity of the neuronal nicotinic acetylcholine receptor $\beta 4$ subunit promoter in transfected PC12 cells. J Neurochem 62:392-395.

Hu M, Bigger CB, Gardner PD (1995) A novel regulatory element of a nicotinic acetylcholine receptor gene interacts with a DNA-binding activity enriched in rat brain. J Biol Chem 270:4497-4502.

Jainchill JL, Aaronson SA, Todaro GJ (1969) Murine sarcoma and leukemia viruses: assay using clonal lines of contact-inhibited mouse cells. J Virol 4:549-553.

Kamachi Y, Sockanathan S, Liu Q, Breitman M, Lovell-Badge R, Kondoh $\mathrm{H}$ (1995) Involvement of SOX proteins in lens-specific activation of crystallin genes. EMBO J 14:3510-3519.

Klebe RJ, Chen T, Ruddle FH (1970) Controlled production of proliferating somatic cell hybrids J Cell Biol 45:74-82.

Kuhlbrodt K, Herbarth B, Sock E, Hermans-Borgmeyer I, Wegner M (1998a) Sox10, a novel transcriptional modulator in glial cells. J Neurosci 18:237-250.

Kuhlbrodt K, Schmidt C, Sock E, Pingault V, Bondurand N, Goossens M, Wegner M (1998b) Functional analysis of Sox10 mutations found in human Waardenburg-Hirschsprung patients. J Biol Chem 273:23033-23038.

McDonough J, Deneris E (1997) $\beta 43^{\prime}$ : an enhancer displaying neuralrestricted activity is located in the $3^{\prime}$-untranslated exon of the rat nicotinic acetylcholine receptor $\beta 4$ gene. J Neurosci 17:2273-2283.

McGehee DS, Role LW (1995) Physiological diversity of nicotinic acetylcholine receptors expressed by vertebrate neurons. Annu Rev Physiol 57:521-546.

Milton NGN, Bessis A, Changeux J-P, Latchman DS (1996) Differential regulation of neuronal nicotinic acetylcholine receptor subunit gene promoters by Brn-3 POU family transcription factors. Biochem $\mathrm{J}$ 317:419-423.

Monuki E, Kuhn R, Weinmaster G, Trapp B, Lemke G (1990) Expression and activity of the POU transcription factor SCIP. Science 249:1300-1303.

Monuki ES, Kuhn R, Lemke G (1993) Cell-specific action and mutable structure of a transcription factor effector domain. Proc Natl Acad Sci USA 90:9978-9982.

Nordeen S (1988) Luciferase reporter gene vectors for analysis of promoters and enhancers. Biotechniques 6:454-457. 
Pevny LH, Lovell-Badge R (1997) Sox genes find their feet. Curr Opin Genet Dev 7:338-344.

Pingault V, Bondurand N, Kuhlbrodt K, Goerich DE, Pr $\theta$ hu M-O, Puliti A, Herbarth B, Hermans-Borgmeyer I, Legius E, Matthijs G, Amiel J, Lyonnet S, Ceccherini I, Romeo G, Smith JC, Read AP, Wegner M, Goossens M (1998) SOX10 mutations in patients with WaardenburgHirschsprung disease. Nat Genet 18:171-173.

Pusch C, Hustert E, Pfeifer D, Südbeck P, Kist R, Roe B, Wang Z, Balling R, Blin N, Scherer G (1998) The SOX10/Sox10 gene from human and mouse: sequence, expression, and transactivation by the encoded HMG domain transcription factor. Hum Genet 103:115-123.

Role LW, Berg DK (1996) Nicotinic receptors in the development and modulation of CNS synapses. Neuron 16:1077-1085.

Schoepfer R, Conroy WG, Whiting P, Gore M, Lindstrom J (1990) Brain $\alpha$-bungarotoxin binding protein cDNAs and MAbs reveal subtypes of this branch of the ligand-gated ion channel gene superfamily. Neuron $5: 35-48$.

Southard-Smith EM, Kos L, Pavan WJ (1998) Sox10 mutation disrupts neural crest development in Dom Hirschsprung mouse model. Nat Genet 18:60-64.

Topp WC (1981) Normal rat cell lines deficient in nuclear thymidine kinase. Virology 113:408-411.

van de Wetering M, Oosterwegel M, van Norren K, Clevers H (1993) Sox-4, an Sry-like HMG box protein, is a transcriptional activator in lymphocytes. EMBO J 12:3847-3854.
Wegner M (1999) From head to toes: the multiple facets of Sox proteins. Nucleic Acids Res 27:1409-1420.

Wright EM, Snopek B, Koopman P (1993) Seven new members of the Sox gene family expressed during development. Nucleic Acids Res 21:744.

Yang X, McDonough J, Fyodorov D, Morris M, Wang F, Deneris ES (1994) Characterization of an acetylcholine receptor $\alpha 3$ gene promoter and its activation by the POU domain factor SCIP/Tst-1. J Biol Chem 269:10252-10264.

Yang X, Fyodorov D, Deneris ES (1995) Transcriptional analysis of acetylcholine receptor $\alpha 3$ gene promoter motifs that bind Sp1 and AP2. J Biol Chem 270:8514-8520.

Yang X, Yang F, Fyodorov D, Wang F, McDonough J, Herrup K, Deneris E (1997) Elements between the protein-coding regions of the adjacent $\beta 4-\alpha 3$ acetylcholine receptor genes direct neuron-specific expression in the central nervous system. J Neurobiol 28:311-324.

Yuan HB, Corbi N, Basilico C, Daily L (1995) Developmental-specific activity of the FGF-4 enhancer requires the synergistic action of Sox2 and Oct-3. Genes Dev 9:2635-2645.

Zoli M, Le Novere N, Hill JA, Changeux J-P (1995) Developmental regulation of nicotinic $\mathrm{ACh}$ receptor subunit mRNAs in the rat central and peripheral nervous systems. J Neurosci 15:1912-1939.

Zwilling S, K $\div$ nig $\mathrm{H}$, Wirth T (1995) High mobility group protein 2 functionally interacts with the POU domains of octamer transcription factors. EMBO J 14:1198-1208. 